\title{
Optimization technology for group hole drainage of coal mining above deep high pressure and low permeability limestone aquifer
}

Haifeng Lu ( $\sim$ luhaifeng7571@126.com )

Anhui University of Science and Technology https://orcid.org/0000-0002-2286-0998

Yuan Zhang

Anhui University of Science and Technology

Manman Zhang

Anhui University of Science and Technology

Guifang zhang

Anhui University of Science and Technology

\section{Research}

Keywords: Prevention and control of coal mine water disaster, Drainage for decreasing water pressure, Aquifer permeability, Multiobjective optimization

Posted Date: April 28th, 2020

DOI: https://doi.org/10.21203/rs.3.rs-21574/v1

License: (c) (i) This work is licensed under a Creative Commons Attribution 4.0 International License. Read Full License 


\title{
Optimization technology for group hole drainage of coal mining above deep high pressure and low permeability limestone aquifer
}

\author{
LU Haifeng, ZHANG Yuan,ZHANG Manman,ZHANG Guifang \\ (School of Earth and Environment, Anhui University of Science and Technology,Huainan,232001,China)
}

\begin{abstract}
Drainage for decreasing water pressure is one of the effective measures to prevent and control water disaster caused of coal mining above high pressure limestone aquifer. The deep limestone aquifer in Huaibei mining area generally has the characteristics of high water pressure, low permeability and uneven water abundance so it is generally difficult to meet the requirements for single-hole drainage. In order to achieve the best drainage effect and consider the requirements of engineering quantity and environmental protection, a multi-objective group hole drainage optimization model was established, which takes the minimum of single-hole flow rate and hole number as the objective function and the requirements of drainage borehole and water level control point drawdown as the constraint conditions. And the particle swarm optimization algorithm was used to solve the model. On this basis, the influence of permeability coefficient and water storage coefficient on the calculation results was discussed. The results show that the permeability coefficient and water storage coefficient have great influence on the optimization of single-hole flow rate and the number of holes. For the low permeability aquifer, measures such as using partially penetrated well, appropriately increasing the number of drainage boreholes and reducing the single-hole flow rate have good drainage effect. And the drilling work amount and total drainage amount are relatively small. These are all good layout schemes for drainage. According to the results of optimization, the drainage of a coal face in Huaibei was guided and achieved good results.
\end{abstract}

Key words: Prevention and control of coal mine water disaster; Drainage for decreasing water pressure; Aquifer permeability; Multiobjective optimization

\section{Introduction}

Coal is one of the main energy sources in China for a long time. Safe and effective mining is a major event related to the national economy and people's livelihood. At present, most of China's coal production comes from North China type coal field. In recent years, with the increase of mining depth, the karst fissure water from Carboniferous Taiyuan formation and Ordovician limestone has increased the threat to the coal mining of the lower coal group(Yuan,1990; Wu et al., 2014;Wu et al.,2017). According to incomplete statistics, in recent years, most of the major water inrush accidents that have occurred in China are caused by the karst fissure water in the coal seam floor penetrating into the working face, causing a large number of casualties. In the past few decades, many scholars have studied the prevention and control of karst fissure water disaster and achieved fruitful results. They put forward the theories of "water bursting coefficient"(Guo and Liu,1989;Li et al.,2018), "key stratum"(Qian et al.,1995;Qian et al.,2003;Lu et al.,2018), "progressive intrusion"(Wang et al.,1996;Lu et al.,2015), "plate model" (Kostecki and Spearing,2015;Zhang et al.,2005)and "down three zone"(Yin et al.,2016;Li1999; Sun et al.,2012), etc., which all reveal the mechanism of water inrush from various aspects. These theories have played a positive guiding role in mine safety production. However, due to the complexity of rock mass medium, major water inrush accidents from floor still occur from time to time.

Huaibei coal field belongs to North China type. The mining of No.10 coal seam in Huaibei coalfield is generally threatened by the confined water of the underlying Taiyuan formation limestone. As the mine mining moves deeper, the water pressure in the aquifer increases and the risk of water inrush increases. At present, drainage mining is one of the common mining methods on confined water. That is to say, the aquifer can be drained at a certain flow rate through the construction of drainage borehole on the ground or in the roadway. This reduces the confined head and reduces the aquifer below the "secure hydraulic head" .Finally, the goal of safe mining is achieved. This method is economical and easy to carry out, so it has been widely used in the 
mining of lower coal group in Huaibei mining area and achieved good results.

The existing data show that the deep Taiyuan aquifer in Huaibei mining area has the characteristics of "high pressure and low permeability"(Chen et al.,2012;Zheng,2018). Due to the poor permeability of the aquifer, the water pressure decreases rapidly, with a large drop depth. The shape of the drain funnel is V-shaped, with a small impact radius. In order to improve the drainage effect, measures such as infill drainage borehole are generally taken. However, the increase of drainage borehole has increased the production cost of coal mines, and at the same time, drainage has also brought certain damage to groundwater resources. This has a serious impact on the sustainable development of the mining area. Therefore, under the condition of satisfying safe production, the total amount of water drainage and the amount of drilling work should be reduced to the greatest extent, thus achieving the best balance among safety, economy and environmental benefits. This is the fundamental starting point for the optimization of the drainage project.

As far as the author knows, there are many research results on optimal design in water resources management and other aspects at present(Song et al.,2016;Wang et al.,2012;Zhao and He,2015;Ali and Kavehkhalili,2015;Andrea et al.,2011). However, there are few research results on optimal design of drainage for decreasing water pressure of limestone in coal mine floor. However, there are few research results on the optimal design of drainage for decreasing water pressure of limestone in coal mine floor. Meng Lei (2015) established the optimal design model of single-hole drainage and gave the optimal layout of drainage borehole(Meng et al.,2015). As mentioned above, the limestone aquifer in deep mining generally has the characteristics of high water pressure, low permeability and uneven water abundance, and it is generally difficult to meet the requirements for single-hole drainage. However, no literature has reported on the optimization of group hole drainage in such aquifers. Therefore, the purpose of this study is to fill up this knowledge gap by optimizing the number of boreholes and the flow rate of boreholes in the group hole drainage, so as to ensure that the goal of drainage is achieved while effectively reducing the cost of coal mining and the degree of damage to the ecological environment. The optimization model proposed in this paper can be used to study the design and calculation of group hole drainage considering the hydrogeological characteristics of aquifer.

\section{Research method}

\subsection{Unsteady well flow of groundwater}

According to the degree of exposing the aquifer and the conditions of water inflow, the drainage borehole can be divided into fully penetrating well and partially penetrated well. The fully penetrating well is a drainage borehole penetrating through the entire aquifer, and the entire wall surface of the borehole can be filled with water, otherwise the drainage borehole is the partially penetrated well (Fig. 1).

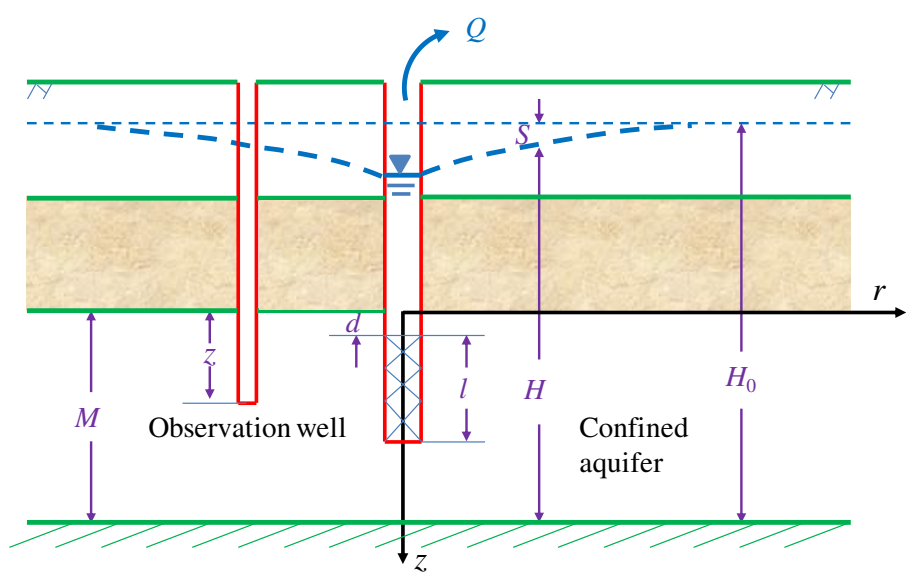

Fig. 1 Schematic diagram of partially penetrated well and observation well in confined aquifer 
If the confined aquifer is in accordance with Theis assumption, when it is partially penetrated well and the straight-line distance $r$ between the observation point and the drainage borehole is $r \leq 1.5 \mathrm{M}$, the drawdown equation is as follows:

$$
S=\frac{Q}{4 \pi K M}\left[W(u)+\zeta\left(\frac{l}{M}, \frac{d}{M}, \frac{r}{M}, \frac{z}{M}\right)\right]
$$

Among them:

$$
\begin{gathered}
\zeta\left(\frac{l}{M}, \frac{d}{M}, \frac{r}{M}, \frac{z}{M}\right)=\frac{4 M}{\pi(l-d)} \sum_{n=1}^{\infty} \frac{1}{n}\left[\sin \left(\frac{n \pi l}{M}\right)-\sin \left(\frac{n \pi d}{M}\right)\right] \cos \left(\frac{n \pi z}{M}\right) K_{0}\left(\frac{n \pi r}{M}\right) \\
u=\frac{r^{2} \mu^{*}}{4 K M t} \\
W(u)=\int_{u}^{\infty} \frac{e^{-x}}{x} d x=-0.577216-\ln u+u-\sum_{m=2}^{\infty}(-1)^{m} \frac{u^{m}}{m \cdot m !}
\end{gathered}
$$

Where, $Q$ is the water discharge of the borehole, $r$ is the straight-line distance between the calculation point and the drainage borehole, $S$ is the water level drawdown; $K$ is the permeability coefficient of aquifer; $M$ is the thickness of the whole aquifer; $u^{*}$ is the elastic release coefficient; $W(u)$ is the fully penetrating well function of Taisi; $u$ is the independent variable of well function; $\zeta$ is the additional resistance coefficient of non integrity; $d$ is the distance from the aquifer roof to the top of the drainage borehole filter; $l$ is the distance from the aquifer roof to the bottom of the drainage borehole filter; $z$ is the distance between the aquifer roof and the bottom of the water level observation hole, i.e. the opening position; $t$ is the drainage time.

It can be seen from formula (1) that the drawdown of partially penetrated well consists of two parts. The former represents the corresponding fully penetrating well drawdown, while the latter represents the additional drawdown caused by streamline bending near the pumping well due to the incompleteness of the pumping well. When the drainage borehole completely penetrates the entire aquifer thickness, the borehole is the fully penetrating well. Or when the straight-line distance $r$ between the observation point and the center of the drainage borehole is $r>1.5 \mathrm{M}$, the additional resistance coefficient can be ignored and simplified as the corresponding fully penetrating well formula, and the drawdown equation is transformed into:

$$
S=\frac{Q}{4 \pi K M}[W(u)]
$$

When the group holes drain water, the water quantity is $Q_{1}, Q_{2}, \ldots Q_{\mathrm{n}}$ respectively. The head drawdown at any point can be calculated according to the seepage superposition principle, that is, it is equal to the sum of the head drawdown of each single drainage borehole, as shown in the following formula.

$$
\left\{\begin{array}{c}
S=\sum_{i=1}^{n} \frac{Q_{i}}{4 \pi K M}\left[W\left(u_{i}\right)+\zeta\left(\frac{l_{i}}{M}, \frac{d_{i}}{M}, \frac{r_{i}}{M}, \frac{z_{i}}{M}\right)\right] \\
S=\sum_{i=1}^{n} \frac{Q_{i}}{4 \pi K M}\left[W\left(u_{i}\right)\right]
\end{array}\right.
$$




\subsection{Optimization problem}

\subsubsection{Water level control point and its safe water level}

In order to achieve the goal of safe mining, the aquifer is drained at a certain flow rate and lowered below the " secure hydraulic head". The secure hydraulic head value is the key index of drainage mining. The secure hydraulic head refers to the water head pressure that the coal seam floor aquifuge can bear. The smaller the secure hydraulic head value is, the larger the head to be reduced is. If the secure hydraulic head value is greater than the actual hydraulic head value, the mining under pressure can be carried out directly without discharging water. In actual project, the method of water bursting coefficient is generally used to determine the secure hydraulic head of working face, as shown in formula (7).

$$
p=T_{s} M
$$

Where, $M$ is the thickness of the aquifuge, and the unit $\mathrm{m}, T_{s}$ is the critical water inrush coefficient. According to the "detailed rules for the prevention and control of water in coal mines", $T_{s}$ is taken as $0.06 \mathrm{mpa} / \mathrm{m}$ in the section with structural damage and $0.1 \mathrm{mpa} / \mathrm{m}$ in the complete section.

In the actual drainage project, the boundary of the covering working face is taken as the drainage boundary, and the end point of the working face is selected as the water level control point within the drainage boundary to calculate the safe water level. First, determine the elevation $H_{\mathrm{d}}$ of coal seam water-resisting floor (the elevation of the aquifer roof) at each water level control point and initial water level elevation $H_{0}$. Then the safe water pressure is converted into a safe water level by using the formula $H_{\mathrm{s}}=p \times 100+H_{\mathrm{d}}$. Finally, using the formula $S_{\mathrm{s}}=H_{0}-H_{\mathrm{s}}$, the safe water level drawdown at each water level control point is obtained.

\subsubsection{Optimization model}

(1) Objective function

In view of the high pressure and low permeability limestone aquifer, according to the previous description, the single-hole flow rate and the number of drainage boreholes are taken as the objective functions in the optimization model. That is, under the condition of water level drawdown and other constraints, the minimum single-hole flow rate and the number of drainage boreholes are reached, thus protecting groundwater resources to the maximum extent. The objective function can be expressed as follows:

$$
Z=o p t\{Q, n\}
$$

The drainage roadway is generalized as a line segment, and its dip angle is $\theta$. When the coordinates of points $\mathrm{a}$ and $\mathrm{b}$ at both ends of the drainage roadway are $\left(x_{p 1}, y_{p 1}\right)$ and $\left(x_{p 2}, y_{p 2}\right)$, the roadway linear equation $y=a x+b$ can be obtained. Where $a$ is the slope of the straight line, $b$ is the intercept of the straight line, and $\left[x_{p 1}, x_{p 2}\right]$ is the abscissa range of the straight line segment. The total length of roadway is recorded as $L$.

There are $n$ drainage boreholes arranged in the drainage roadway, which are $F_{1}, F_{2} . . F_{i} . . F_{n}$. They are arranged according to equal spacing, and the spacing between adjacent boreholes is $D$. The coordinates of any drainage borehole are $\left(x_{\mathrm{ci}}, y_{\mathrm{ci}}\right)$. There are $m$ water level control points in the working face, which are $C_{1}, C_{2} \ldots \mathrm{C}_{\mathrm{j}}$, $\mathrm{C}_{\mathrm{m}}$, coordinate of any control point is $\left(x_{\mathrm{j}}, y_{\mathrm{j}}\right)$. The distance from any drainage borehole to any water level control point is recorded as $r_{\mathrm{ij}}$. It is assumed that the discharge capacity of each drainage borehole is equal, all of which

are $Q$. The drainage borehole and water level control points are shown in Fig. 2. Then the minimum optimization models of $Q$ and $n$ are $\min (Q)$ and $\min (n)$. 


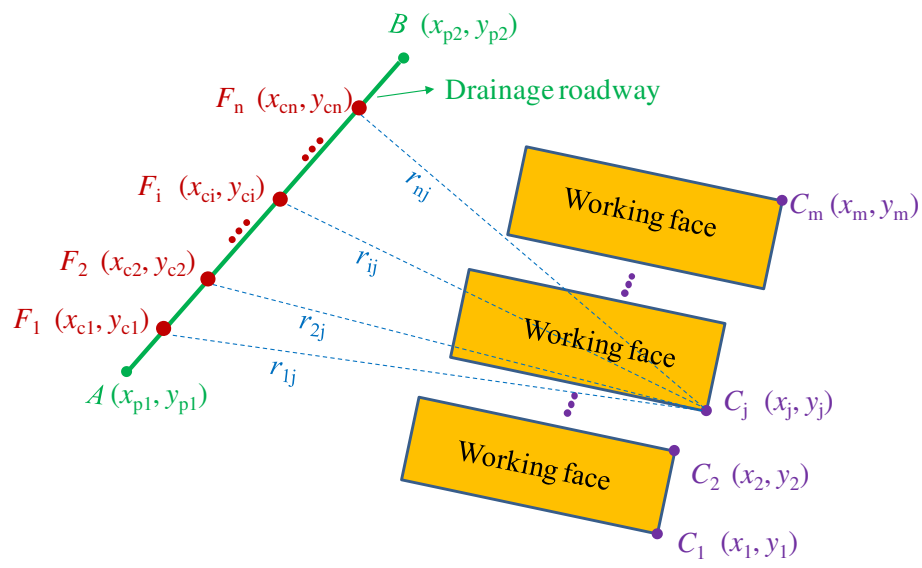

Fig. 2 Layout diagram of arrangement of drainage borehole

On the premise of safe mining, the single-hole flow rate and the number of boreholes are minimized. Then the best position of the drainage borehole in the roadway will directly affect the realization of the optimization goal.

(2) Constraints condition :

1) Constraint condition of hole number

As shown in Fig. 2, the lower left corner of the roadway is set as the layout position of the first drainage borehole $\left(x_{1}, y_{1}\right)$. In addition, the drainage borehole shall not exceed the scope of drainage roadway. According to the coordinates of the roadway end points and the roadway straight line equation, the constraint conditions for the number $n$ of drainage borehole in this group hole can be written as follows:

$$
\left\{\begin{array}{c}
n=\left[\frac{L-\sqrt{\left(x_{p 1}-x_{c 1}\right)^{2}+\left(y_{p 1}-y_{c 1}\right)^{2}}}{D}\right]>1 \\
0<D \leq L-\sqrt{\left(x_{p 1}-x_{c 1}\right)^{2}+\left(y_{p 1}-y_{c 1}\right)^{2}} \\
x_{c 1} \leq x_{p 1}, x_{c 1}+(n-1) D \cos \theta \leq x_{p 2} \\
\theta=\arctan a
\end{array}\right.
$$

\section{2) Constraint conditions of flow}

When the water level of the drainage borehole drops to the aquifer roof $\left(S_{\max }\right)$, the drainage flow of the borehole is recorded as $Q_{\max }$. The flow rate is the maximum value constraint condition of single-hole flow rate in optimization, that is, the upper limit value of flow rate. If the radius of the drainage borehole is $r_{\mathrm{w}}$, considering the mutual interference between the drainage holes, the flow constraints are as follows:

- When the drainage borehole is a full penetrating well or a partially penetrated well but the distance $D$ between boreholes is not less than $D \geq 1.5 M$, the $i$-th drainage borehole is:

$$
Q \leq \frac{4 \pi K M S_{\max }}{W\left(u_{r_{(i-1) D}}\right)+\cdots+W\left(u_{r_{D}}\right)+W\left(u_{r_{w}}\right)+W\left(u_{r_{D}}\right)+\cdots+W\left(u_{r_{(n-i) D}}\right)}
$$

- The drainage borehole is a partially penetrated well. If the distance $D$ between boreholes is less than $1.5 M$, when the mutual interference of the non-integrity additional resistance coefficient $\zeta$ is not considered, the $i$-th drainage borehole is: 


$$
Q \leq \frac{4 \pi K M S_{\max }}{W\left(u_{r_{(i-1) D}}\right)+\cdots+W\left(u_{r_{D}}\right)+W\left(u_{r_{w}}\right)+W\left(u_{r_{D}}\right)+\cdots+W\left(u_{r_{(n-i) D}}\right)+n \zeta\left(\frac{l}{M}, \frac{d}{M}, \frac{r_{w}}{M}, \frac{Z}{M}\right)}
$$

3) Constraint conditions of water level drawdown at control points

The drawdown of water level at all control points shall reach the purpose of safe mining. For any $j$-th water level control point, the safe water level drawdown is $S_{s j}$, and its constraint conditions are as follows:

- When the drainage borehole is a full penetrating well or a partially penetrated well but $r \geq 1.5 \mathrm{M}$, there are:

$$
\sum_{i=1}^{n} \frac{Q}{4 \pi K M}\left[W\left(u_{i j}\right)\right] \geq S_{s j}
$$

- When the drainage borehole is a partially penetrated well and the straight-line distance $r$ between the water level control point and the drainage borehole is $r \leq 1.5 \mathrm{M}$, there are:

$$
\sum_{i=1}^{n} \frac{Q}{4 \pi K M}\left[W\left(u_{i j}\right)+\zeta\left(\frac{l_{i}}{M}, \frac{d_{i}}{M}, \frac{r_{i}}{M}, \frac{z_{i}}{M}\right)\right] \geq S_{s j}
$$

\subsubsection{Straight-line distance}

In view of the problem of drainage of limestone aquifer with high pressure and low permeability, due to the strong heterogeneity of aquifer water abundance, the form of infilling drainage borehole is generally adopted to realize the safe mining in the whole working face. However, if too many boreholes are constructed, the mining cost will be increased. If the boreholes are reduced, the water discharge of single hole will be increased. However, due to the characteristics of low permeability, single hole drainage should not be too large, otherwise the effect of drainage is poor. Therefore, the objective of this optimization is to construct the least drainage borehole and minimize the single-hole flow under the constraint conditions, which is a multi-objective optimization problem. In this paper, multi-objective particle swarm optimization (MOPSO) algorithm is used to solve the problem. This algorithm was proposed by Coello et al in 2002 (Coello and Lechuga,2002), which extends particle swarm optimization to multi-objective optimization design. This algorithm has been recognized as a classical multi-objective particle swarm optimization algorithm. The core of this algorithm is how to choose the best pbest in history. For multi-targets, the comparison of two particles can't compare which one is better. A particle is better if each of its targets is better. If some are better and some are worse, it is impossible to say which is better or which is worse strictly. For multiple objectives, there are many optimal individuals. Each particle can only choose one as the best individual in the algorithm. The flow chart of MOPSO algorithm is shown in Fig. 3 (a), and the establishment and calculation flow of this optimization model is shown in Fig. 3 (b). 
(a)

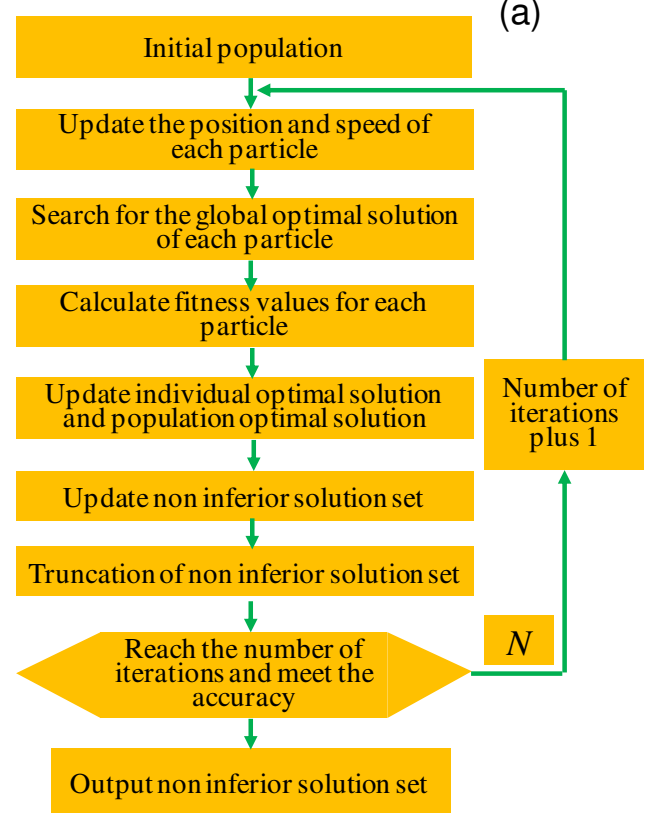

(b)

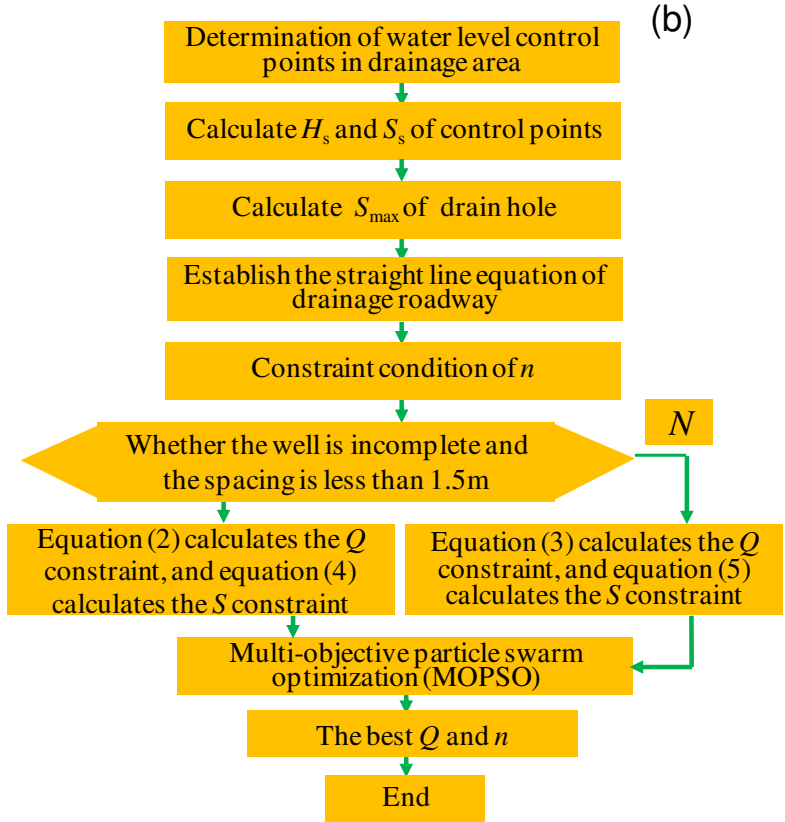

Fig. 3 Calculation flow chart of optimization model. (a) MOPSO algorithm and (b) model establishment and solution

\section{Example application and discussion}

\subsection{Engineering background}

Suntuan coal mine is located in the southwest of Huaibei coalfield, in the northern area of Anhui Province, China..The No.10 coal seam is about $35-55 \mathrm{~m}$ away from the top of the confined aquifer of Taiyuan formation limestone (Fig. 4). There are 12 layers limestone $\left(L_{1}-L_{12}\right)$ in the Taiyuan formation of mine field ,The total thickness of Taiyuan formation is $85-130 \mathrm{~m}$. And the accumulated thickness of limestone is $45-70 \mathrm{~m}$, accounting for $60 \%$ of the total thickness of Taiyuan formation. The aquifer of upper 1-4 layers limestone $\left(L_{1}-L_{4}\right)$ is the main factor affecting the safe mining of the No. 10 coal seam. The aquifer below the 5 layer limestone is far away from the No. 10 coal seam. Therefore, the impact on mining is small.

The mine stratum trend is nearly north-south, inclines to east, with an inclination of about $10^{\circ}$, and presents monoclinal structure. Faults are developed in the mine field, most of which are tensional and torsional faults. No large amount of leakage of flushing fluid was found in fault fracture zones of different horizons during drilling. The pumping test data of fault zone show that the unit water inflow $q=0.016-0.00048 \mathrm{~L} /(\mathrm{s} . \mathrm{m})$, the permeability coefficient $K=0.023-0.0017 \mathrm{~m} / \mathrm{d}$, the water inflow is small, and the aquifuge meets the standard. Due to the water blocking effect of faults, the water-bearing rock group in the upper member of Taiyuan formation in the mine field is a closed and weak aquifer, which provides feasibility for drainage for decreasing water pressure mining. 


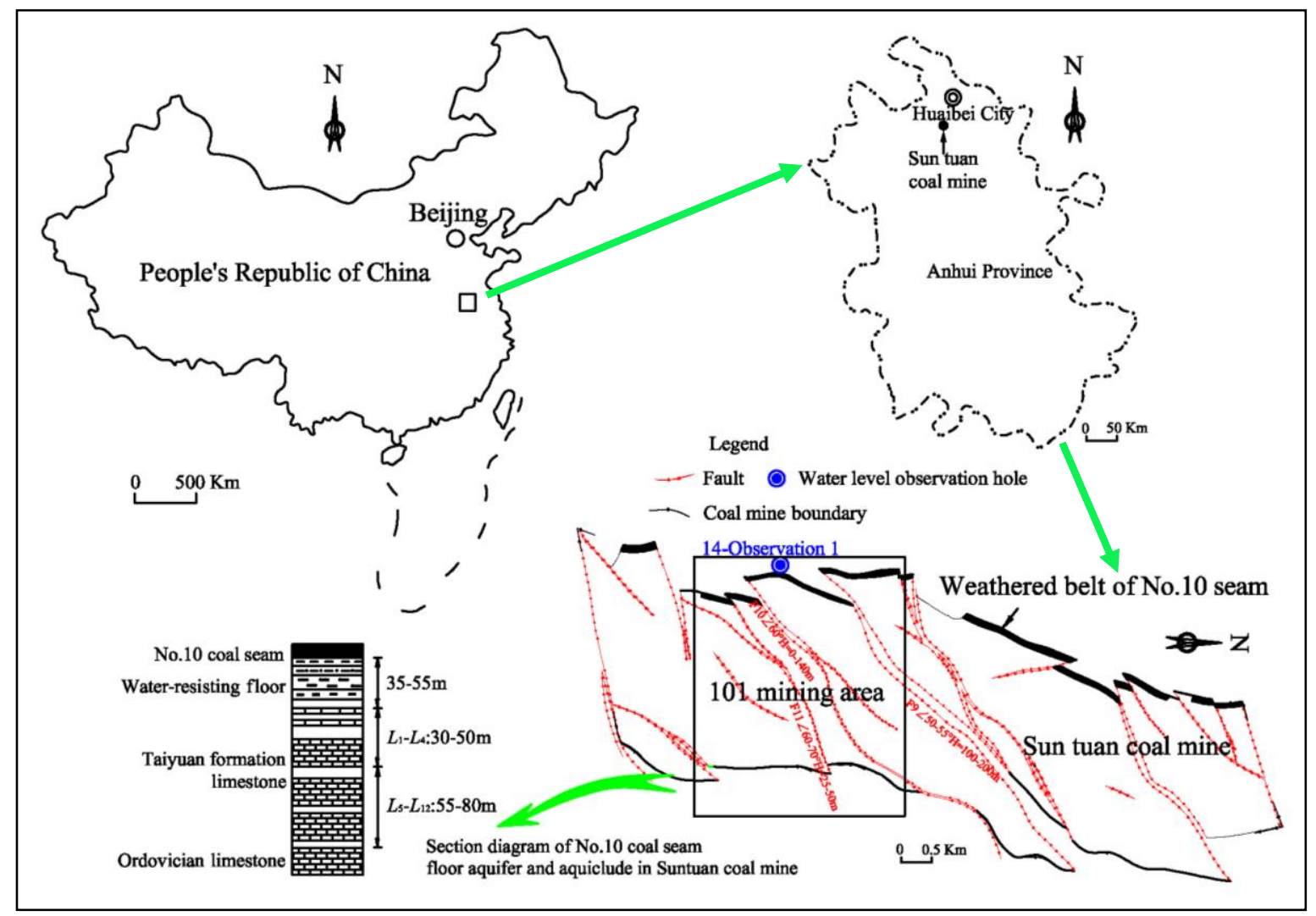

Fig. 4 Location of study area

In the exploration and mining stage, 22-23-1, 27-1 and 07 observation 3 boreholes have been successively drilled in the mine to carry out pumping test on $L_{1}-L_{4}$ aquifer, and the hydrogeological parameter results are as shown in Fig.1.

Table 1 Pumping test of $L_{1}-L_{4}$ aquifer

\begin{tabular}{|c|c|c|c|c|}
\hline Borehole & $\begin{array}{c}\text { Aquifer roof elevation } \\
H_{\mathrm{d}}(\mathrm{m})\end{array}$ & $\begin{array}{c}\text { Initial water } \\
\text { level elevation } \\
H_{0}(\mathrm{~m})\end{array}$ & $\begin{array}{c}\text { Unit water inflow } q \\
(\mathrm{~L} / \mathrm{s} . \mathrm{m})\end{array}$ & $\begin{array}{c}\text { Permeability coefficient } \\
K(\mathrm{~m} / \mathrm{d})\end{array}$ \\
\hline $22-23-1$ & -261.2 & +19.91 & 0.058 & 0.21 \\
\hline $27-1$ & -320.59 & +21.12 & 0.055 & 0.17 \\
\hline 07 observation 3 & -210.32 & +18.39 & 0.77 & 2.99 \\
\hline 14 observation 1 & -205.35 & +1.22 & 1.55 & 3.93 \\
\hline $25-26-S 1$ & -878.13 & +14.22 & 0.0082 & 0.026 \\
\hline $13-14-S 4$ & -565.36 & +14.20 & 0.0052 & 0.027 \\
\hline 11 observation 2 & -220.35 & +21.1 & 0.093 & 0.28 \\
\hline
\end{tabular}

As can be seen from Table 1, $q=0.0052-0.773 \mathrm{~L} / \mathrm{s} . \mathrm{m}), K=0.026-3.93 \mathrm{~m} / \mathrm{d}$, with strong water abundance and connectivity at the shallow concealed outcrop, gradually weakening to a weak permeable layer towards the deep. In addition, the $q$ and $K$ values of different boreholes are quite different, which further illustrates the heterogeneity of water abundance and permeability of the upper limestone aquifer of Taiyuan formation. The karst fissure aquifer in deep mine has the characteristics of high pressure and low permeability.

1013 and 1011 working faces are located in 101 mining area, which is divided into several blocks by several large faults F9, F10 and F11. The two working faces are located in the middle of F9 and F10 faults (Fig. 4), and the hydrogeology conditions are relatively independent. Under the working face lies the high pressure limestone aquifer of Taiyuan formation, in which the thickness of $L_{1}-L_{4}$ aquifer is $50 \mathrm{~m}$. Among 126 water 
exploration boreholes in the upper part of the Taiyuan formation limestone $\left(L_{1}-L_{4}\right)$ aquifer in the mining area, there were only 4 boreholes with water output of more than $5 \mathrm{~m}^{3} / \mathrm{h}$, most of them were dry holes, and the water output rate was less than $2 \%$. It was further confirmed that the limestone aquifer on the bottom plate is insufficient in supply and has good drainage. Since the mine was put into operation in 2007, the limestone aquifer of Taiyuan formation has been drained. Before the mining of the two working faces, the water level elevation of Taiyuan limestone water level observation hole 14- observation 1 hole in the mining area is $-50 \mathrm{~m}$, and the minimum aquifuge thickness of coal seam and aquifer is $45 \mathrm{~m}$. According to the calculation of the lowest elevation of the working face $-515 \mathrm{~m}$, the maximum water pressure on the bottom of the aquifuge is 4.65 $\mathrm{MPa}$, and the water bursting coefficient is about 0.103 , which is greater than the critical value in the "detailed rules for the prevention and control of water in coal mines", so it is dangerous for water inrush. It is planned to use 1 year for drainage for decreasing water pressure, and the goal is to reduce the water pressure to the critical water bursting coefficient value, so as to ensure safe mining.

According to the drainage characteristics of limestone aquifer in Taiyuan formation with high pressure and low permeability, in order to ensure the smooth mining of the two working faces, a special drainage roadway was constructed in the mine (Fig. 5). Through the construction of drainage borehole, the purpose of drainage mining was achieved. The floor elevation of the drainage roadway is $-541.9--540.7 \mathrm{~m}$, with a total length of $390 \mathrm{~m}$. The following will carry out the optimization calculation of the drainage borehole in the drainage roadway. According to the hydrological exploration report, the aquifer thickness of $L_{1}-L_{4}$ in the mining area is $50 \mathrm{~m}$, the permeability coefficient $K$ is $0.03 \mathrm{~m} / \mathrm{d}$, and the water storage coefficient is $1 \times 10^{-6}$. The radius of drainage borehole $r_{\mathrm{w}}$ is $0.05 \mathrm{~m}$, and the maximum drawdown of single hole $S_{\max }$ is $490 \mathrm{~m}$.

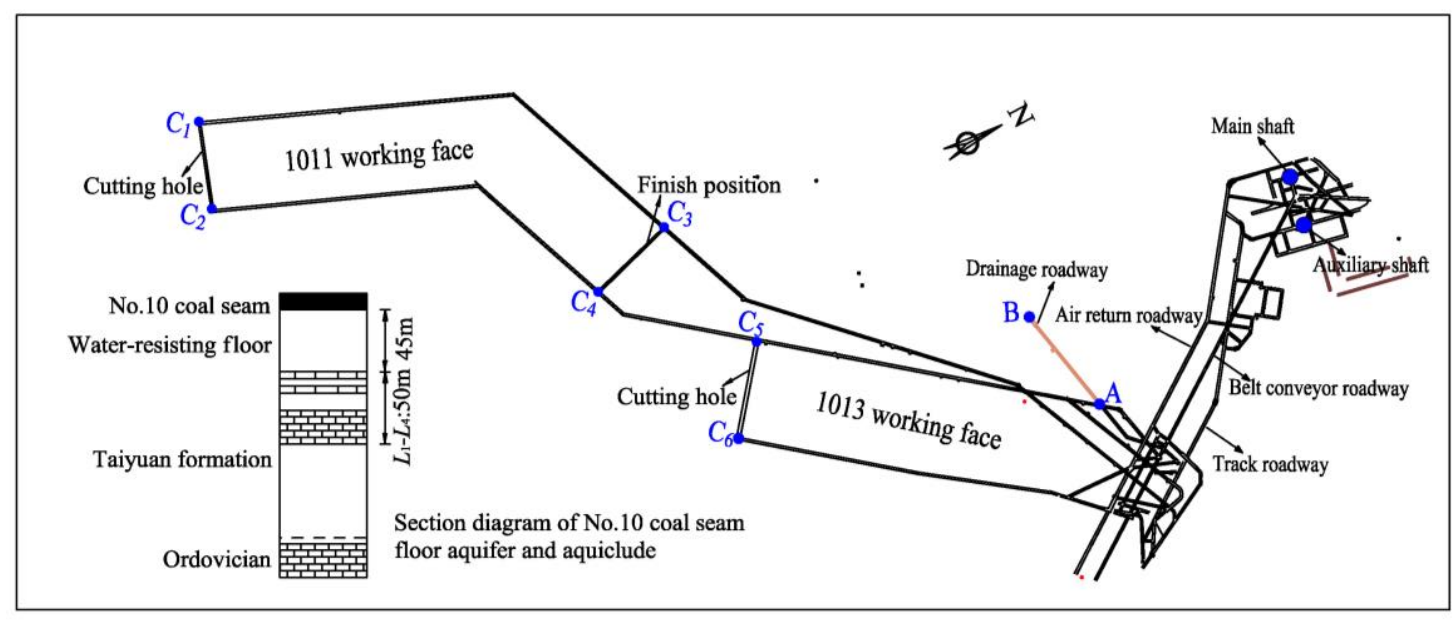

Fig. 5 Location of working face and water level control point in mining area

\subsection{Establishment and solution of optimization model}

According to the selection principle of water level control points, the end of the upper and lower roadway far away from the drainage borehole and the working face with large buried depth is the control point, as shown in Fig. 1. Each control point is the observation point of water level, which is the water pressure at the bottom of the aquifuge of the coal seam floor, i.e. $z=0$, and $d=0$ of the drainage borehole. To facilitate calculation, take the lower left corner of Fig. 5 as the coordinate origin, and get the relative coordinates of each control point as shown in the table below. According to the detailed rules for the prevention and control of water in coal mines and the mining practice in Huaibei, the critical water bursting coefficient of the working face is $0.06 \mathrm{MPa} / \mathrm{m}$, and the safe water pressure at the control point is $2.7 \mathrm{MPa}$. According to the water head formula, the safe water level at the control points and the safe water level drawdown at each control point are shown in Table 2. 
Table 2 Safe drawdown of water level control point

\begin{tabular}{|c|c|c|c|c|c|}
\hline $\begin{array}{c}\text { Control point } \\
\text { number }\end{array}$ & $x$ & $y$ & $\begin{array}{c}\text { Bottom elevation } \\
\text { of aquifuge } \\
H_{\mathrm{d}}(\mathrm{m})\end{array}$ & $\begin{array}{c}\text { Secure hydraulic head } \\
\text { elevation of control point } \\
H_{\mathrm{s}}(\mathrm{m})\end{array}$ & $\begin{array}{c}\text { Secure hydraulic } \\
\text { head drawdown of } \\
\text { control point } S_{\mathrm{s}} \\
(\mathrm{m})\end{array}$ \\
\hline $\mathrm{C}_{1}$ & 360.26 & 971.06 & -360 & -90 & 40 \\
\hline $\mathrm{C}_{2}$ & 381.85 & 790.39 & -390 & -120 & 70 \\
\hline $\mathrm{C} 3$ & 1263.51 & 774.97 & -425 & -155 & 105 \\
\hline $\mathrm{C} 4$ & 1144.15 & 643.54 & -450 & -180 & 130 \\
\hline $\mathrm{C} 5$ & 1427.15 & 338.74 & -540 & -270 & 220 \\
\hline $\mathrm{C} 6$ & 1787.30 & 269.39 & -565 & -295 & 245 \\
\hline
\end{tabular}

The drainage borehole is planned to be arranged in section $A B$ of the roadway. According to the coordinates of $A(2008.42,582.83)$ and $B(2146.8,408.48)$, it can be concluded that the roadway can be generalized into a linear equation as $y=-1.23 x+3057.4(2008.42 \leq x \leq 2146.8)$. According to the formula (1) and (2) of the optimization model, the model is solved by using the multi-objective particle swarm optimization algorithm based on Matlab software, and the calculation results are shown in Table 3. Fig. 6 is the solution of all the constraints given by the example of a fully penetrating well. The program gives the final result according to the optimization objective of small number of holes and small flow of single hole, combined with the principle of minimum total flow.

Table 3 Optimization results

\begin{tabular}{|c|c|c|c|c|c|c|}
\hline$l / \mathrm{M}$ & $n$ & $\begin{array}{c}\text { first hole } \\
\text { coordinates } x(\mathrm{~m})\end{array}$ & $\begin{array}{c}\text { Spacing } D \\
(\mathrm{~m})\end{array}$ & Flow $Q\left(\mathrm{~m}^{3} / \mathrm{d}\right)$ & $\begin{array}{c}\text { Drilling quantities } \\
l \times n(\mathrm{~m})\end{array}$ & $\begin{array}{c}\text { Total flow } Q \times n \\
\left(\mathrm{~m}^{3} / \mathrm{d}\right)\end{array}$ \\
\hline $\begin{array}{c}\text { 1(fully } \\
\text { penetrating well) }\end{array}$ & 4 & 2012.2 & 62.17 & 131.05 & 200 & 524.2 \\
\hline $\begin{array}{c}0.8 \text { (partially } \\
\text { penetrated well) }\end{array}$ & 5 & 2008.4 & 51.23 & 104.9 & 200 & 524.5 \\
\hline $\begin{array}{c}0.6 \text { (partially } \\
\text { penetrated well) }\end{array}$ & 6 & 2008.4 & 39.02 & 87.33 & 180 & 523.98 \\
\hline $\begin{array}{c}0.4 \text { (partially } \\
\text { penetrated well) }\end{array}$ & 8 & 2036.1 & 24.76 & 65.91 & 160 & 527.31 \\
\hline $\begin{array}{c}0.2 \text { (partially } \\
\text { penetrated well) }\end{array}$ & 16 & 2034.1 & 11.69 & 32.9 & 160 & 526.4 \\
\hline
\end{tabular}

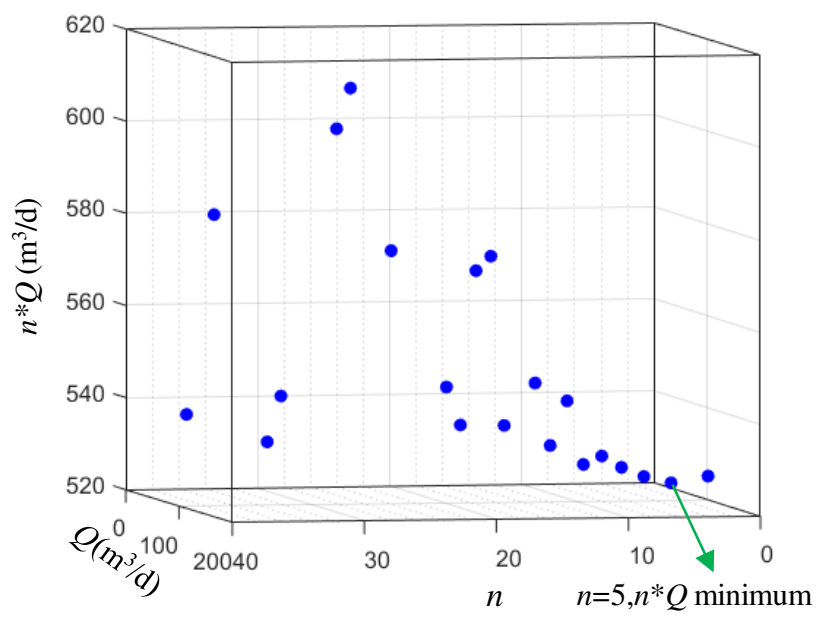

Fig. 6 Solutions for all constraints of a fully penetrating well

It can be seen from Table 3 that when the drainage borehole is a fully penetrating well, the optimal number 
of drain holes is calculated as $n=4$, the spacing between holes is $62.17 \mathrm{~m}$, the discharge of single hole is $131.05 \mathrm{~m}^{3} / \mathrm{d}$, and the total discharge is $524.2 \mathrm{~m}^{3} / \mathrm{d}$. When it is a partially penetrated well, with the decrease of $l / \mathrm{M}$, that is to say, the smaller the degree of drilling through the aquifer, the more $n$, the larger the increase, the smaller the single hole flow and the little difference in the total flow. However, the total amount of drilling work shows the trend of decreasing step by step. For the low permeability heterogeneous aquifer, from the above, through the infilling drilling, single hole small flow can achieve better drainage effect. However, when the flow rate of single hole is small, there are many holes and high construction cost. At the same time, the aquifer is a composite aquifer composed of $L_{1}-L_{4}$. Generally, the water abundance of $L_{3}-L_{4}$ is better. If the $l / M$ is smaller, there is a problem that it is difficult to enter $L_{3}-L_{4}$ by drainage borehole. According to the results of this optimization calculation, when $l / M=0.6$, the number of holes, the amount of drilling work is moderate, and the total water discharge is also the smallest, which is an ideal water discharge design scheme.

\subsection{Parameter discussion}

(1) Aquifer permeability

In order to study the influence of aquifer permeability on drainage, when the fixed water storage coefficient $u^{*}$ is $1 \times 10^{-6}$ and the permeability coefficient $K$ value is between $0.008 \mathrm{~m} / \mathrm{d}-0.1 \mathrm{~m} / \mathrm{d}$, the optimal $n$ and $Q$ are obtained respectively, as shown in Fig. 7. It can be seen from Fig. 7 that with the gradual increase of $K$, the low permeability of the aquifer changes from low to high, and $n$ shows the phenomenon of first decreasing and then rising, and $n$ is the smallest when $K=0.03 \mathrm{~m} / \mathrm{d}$. This shows that the effect of drainage in low permeability aquifer is better when the measures such as infilling drainage hole and reducing single hole flow are taken. In addition, with the increase of $K$ value, the flow rate $Q$ of single hole increases generally, but when $K$ value reaches a certain high value, with the increase of $n$, the growth of $Q$ appears gentle.
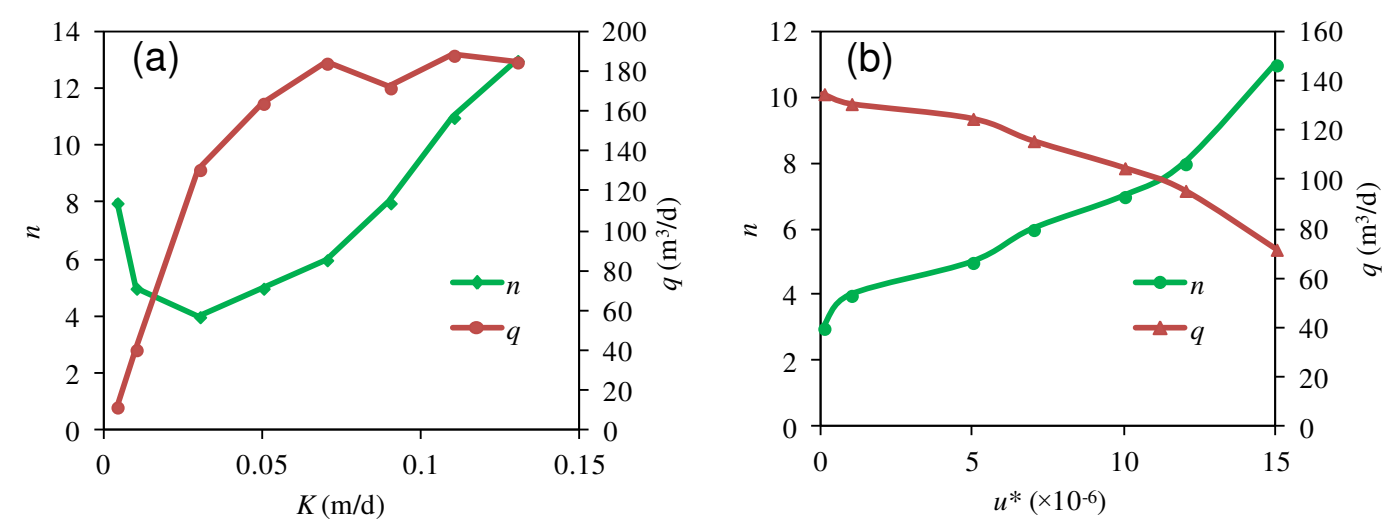

Fig. 7 Influence of hydrogeological parameters on optimization model .(a) $K \quad$ (b) $u^{*}$

(2) Water storage coefficient of aquifer

In order to explore the influence of water storage coefficient on the optimization results, when the fixed permeability coefficient $\mathrm{K}=0.03 \mathrm{~m} / \mathrm{d}$ and the water storage coefficient $u^{*}$ value is between $0.1 \times 10^{-6}-15 \times 10^{-6}$, the optimal $\mathrm{n}$ and $Q$ are obtained respectively, as shown in Fig.6. It can be seen from Fig. 6 that the water storage coefficient reflects the water rich degree of the aquifer. Therefore, with the increase of the water storage coefficient, the number of the optimal drainage holes under the constraint conditions is also increasing step by step, while the single hole flow rate is decreasing step by step, and the total flow rate is increasing step by step.

\subsection{Drainage effect}

In the actual drainage engineering design of the mine, the optimization results are used for reference, the partially penetrated well scheme is adopted, the single hole flow is reduced, the drainage borehole is properly densified and other measures are taken to deal with the drainage problem of the heterogeneous and low permeable limestone aquifer. In the two drilling fields of the drainage roadway, 6 cross limestone layer drainage 
boreholes are arranged (Fig. 8). Except that the final hole of F1-2 is in the limestone of the third Taiyuan formation, the other five drainage boreholes are all in the limestone of the fourth Taiyuan formation. The single hole discharge is concentrated between $52 \mathrm{~m}^{3} / \mathrm{d}$ and $100 \mathrm{~m}^{3} / \mathrm{d}$. In addition, in order to achieve better drainage effect, four nearly horizontal drainage boreholes were constructed along $170^{\circ}, 196^{\circ}, 206^{\circ}$ and $222^{\circ}$ azimuth in No. 3 drilling field of drainage lane. The drainage boreholes are basically parallel to the limestone trend of the fourth Taiyuan formation, with an average length of $140 \mathrm{~m}$.
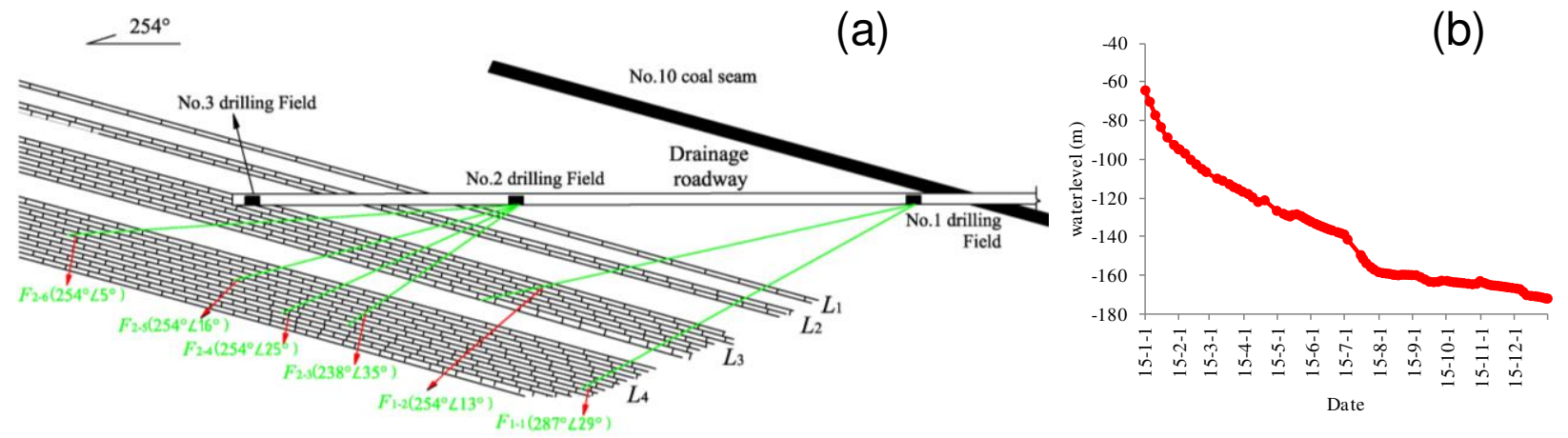

Fig. 8 Layout of drainage works and water level change of observation borehole .(a) drainage layout section (b) water level change of 14 observation 1 hole

As of December 31, 2015, the total discharge of limestone in Taiyuan formation of mining area 101 is $50 \mathrm{~m}^{3} / \mathrm{h}$, with a total discharge of about $490000 \mathrm{~m}^{3}$. The water level of 14 observation 1 (outside the outcrop of the mining area) in the limestone observation hole of Taiyuan formation on the ground decreased from $-50 \mathrm{~m}$ to $-170 \mathrm{~m}$, with a cumulative decrease of $120 \mathrm{~m}$, as shown in Fig. 8 (b). The maximum daily decline is $2.4 \mathrm{~m}$. The water pressure of the underground pressure tap in the working face is $0.2 \mathrm{MPa}$ (corresponding to the water level of $-320 \mathrm{~m}$, and the elevation of the lowest point of the working face mining section is $-401.1 \mathrm{~m}$, and the maximum water bursting coefficient of the working face is $0.026 \mathrm{MPa} / \mathrm{m}$, basically reaching the goal of drainage mining.

It is worth noting that the optimization model of multi hole drainage in this paper is based on the unsteady flow theory of vertical well. For the inclined shaft in the actual project, the conversion method is often used to calculate the drawdown, which has calculation errors. At the same time, the model in this paper is not suitable for the calculation of drawdown of horizontal drainage borehole. At the same time, the model in this paper is not suitable for the calculation of the drawdown of horizontal drainage hole along the limestone layer. However, the optimization model in this paper still has certain guiding significance for the determination of single-hole flow rate, the degree of drainage borehole penetrating the aquifer and the number of holes when it is applied to the drainage of low permeability aquifer.

\section{Conclusion}

In the deep mining, limestone aquifer is characterized by high water pressure, low permeability and uneven water abundance, so it is difficult to meet the requirements of single hole drainage. Based on the characteristics of low permeability of aquifer and the requirements of economy and environmental protection, this paper establishes a multi-objective multi hole drainage optimization model, which takes the single-hole flow rate and the minimum number of holes as the objective function, and takes the requirements of drainage boreholes and the drawdown of water level control points as the constraints. and is applied to a coal mining face in Huaibei. The main conclusions are as follows:

(1) When the degree of drainage borehole penetrating the aquifer $(l / M)$ is smaller, the number of optimized water drainage holes $n$ increases gradually, and the increasing range increases gradually. The single-hole flow 
rate gradually decreases, but the total flow rate has little difference. At the same time, the total amount of drilling work shows the trend of decreasing step by step. In view of the low permeability heterogeneous aquifer, it is a better drainage design scheme to use the partially penetrated well, increase the number of drainage boreholes, reduce the single-hole flow rate and other measures appropriately, with better drainage effect, and relatively small drilling quantities and total drainage.

(2) The hydrogeological parameters have great influence on the optimization results. With the increase of the permeability coefficient $K$ of the aquifer, the number of the optimal drainage boreholes decreases first and then increases, while the single-hole flow rate $Q$ increases monotonously, but the increase tends to decrease. With the increase of water storage coefficient, the number of optimal drainage boreholes increases step by step, and the single-hole flow rate decreases step by step.

(3) According to the characteristics that the upper aquifer of Taiyuan formation is a compound aquifer composed of $L_{1}-L_{4}$ and the lower $L_{3}-L_{4}$ has good water-abundance, it is suggested that the incomplete well should penetrate through the third layer of limestone in the actual drainage project. In addition, for the mine with limestone drainage roadway, the drainage borehole along the limestone layer can be constructed in the roadway. Better drainage effect can be achieved by combining with conventional through layer drainage hole

\section{Acknowledgments}

This study was partially supported with the major projects of natural science research in Higher Education Institutions(KJ2019ZD11) and the research grants from the National Natural Science Foundation of China (41977253). The data used in this paper can be accessed by contacting the corresponding author directly.

\section{References}

Ali Dolatshahi-Zand,KavehKhalili-Damghani,2015.Design of SCADA water resource management control center by a bi-objective redundancy allocation problem and particle swarm optimization. Reliability Engineering \& System Safety,133:11-21.

Andrea Sulisa,Paola Buscarinub,Giovanni M,2011.Sechi.Using reservoir trophic-state indexes in optimisation modelling of water-resource systems. Environmental Modelling \& Software,26(6): 731-738.

Coello C A C, Lechuga M S,2002. MOPSO: a proposal for multiple objective particle swarm optimization.IEEE Congress on Evolutionary Computation, Piscataway,New Jersey, 1051-1056.

Guo W J, Liu Y X,1989. The concept of water in-rush coefficient and its application. Hebei Coal, 2:56-60.

Li B Y,1999."Down three zones" in the prediction of water inrush from coalbed floor aquifer-theory, development and application. Journal of Shandong Institute of Mining and Technology,18(4):11-18.

Lu H, Liang X,Shan N ,Zhang Y K,2018. Study on the stability of the coal seam floor above a confined aquifer using the structural system reliability method. Geofluids,1-15.

Li W, Liu Y, Qiao W, Zhao C, Yang D ,Guo Q,2018. An improved vulnerability assessment model for floor water bursting from a confined aquifer based on the water inrush coefficient method. Mine Water and the Environment,37(1):196-204.

Lu H F, Yao D X, Shen D ,Cao J Y,2015. Fracture mechanics solution of confined water progressive intrusion height of mining fracture floor. Lnternational Journal of Mining Science and Technology, (1):99-106.

Meng L, Feng Q Y, Ding E J,2015. Optimization method for single hole drainage of high pressure water well in coal seam floor. Chinese invention patent: 201510354956.6201506.

Qian M G,Miao X X,Li L J,1995.Mechanical behaviour of main floor for water inrush in longwall mining. Journal of China University of Mining \& Technology, 5(1):9-16.

Qian M G,Miao X X,Xu J L,Mao X B,2003. Key Strata Theory in Ground Control.Xuzhou:China University of Mining and Technology Press.

Sun J, Wang L G, Hou H Q,2012.Application of microseismic monitoring technology in mining engineering. International Journal of Mining Science and Technology,22(1): 79-83.

Song P Z, Wang J Y, Liu W,2016. Water resource security evaluation model based on PSO optimization logic STI curve. Journal of natural resources,31 (5): 886-892. 
T. Kostecki , A. J. S. Spearing,2015.Influence of backfill on coal pillar strength and floor bearing capacity in weak floor conditions in the Illinois Basin. International Journal of Rock Mechanics and Mining Sciences, 76: 55-67.

Wu Q , Fan Z L , Zhang Z W a,Zhou W F,2014.Evaluation and zoning of groundwater hazards in Pingshuo no. 1 underground coal mine, Shanxi Province, China. Hydrogeology Journal, 22(7):1693-1705.

Wu Q, Guo X M.,Shen J J,Xu S, Liu S Q,Zeng Y F,2017.Risk assessment of water inrush from aquifers underlying the Gushuyuan coal mine, China.Mine Water and the Environment,36( 1):96-103.

Wang J M,Ge J D,Wu Y H,1996.Mechanism on progressive intrusion of pressure water under coal seams into protective aquiclude and its application in prediction of water invasion. Journal of Coal Science \& Engineering, 2(2):9-15.

Wang C L,Liu J L, Gui H R, 2012. Numerical simulation of dynamic evolution of potential water inrush area of mining coal seam floor on high pressure water body. China mining,21(3): 81-84.

Wang Z R, Luo B L, Niu Y G,2012. Research and application of decision-making visualization system for optimal allocation of water resources in Dalian.Journal of Dalian University of technology, 52 (2): 259-263.

Yuan L,2019.Scientific problem and countermeasure for precision mining of coal and associated resources. Journal of China Coal Society,44(1):1-9.

Yin H, L. Lefticariu,. Wei J, Guo J, Li Z,Guan Y, 2016.In situ dynamic monitoring of stress revolution with time and space under coal seam floor during longwall mining. Environment and Earth Science, 75(18):1249.

Zhang J C, 2005.Investigations of water inrushes from aquifers under coal seams.Int J Rock Mech Min Sci \& Geomech Abstr, 42:350-360.

Zheng S T,2018. Advanced exploration and treatment technology of limestone water damage area in coal seam floor of Lianghuai coalfield. Coalfield geology and exploration, 46 (4): 142-146.

Zhao X Q,H Z A,2015. Water resources optimal scheduling based on improved chaos genetic algorithm.Journal of Lanzhou University of technology,41(4):65-70. 
Figures

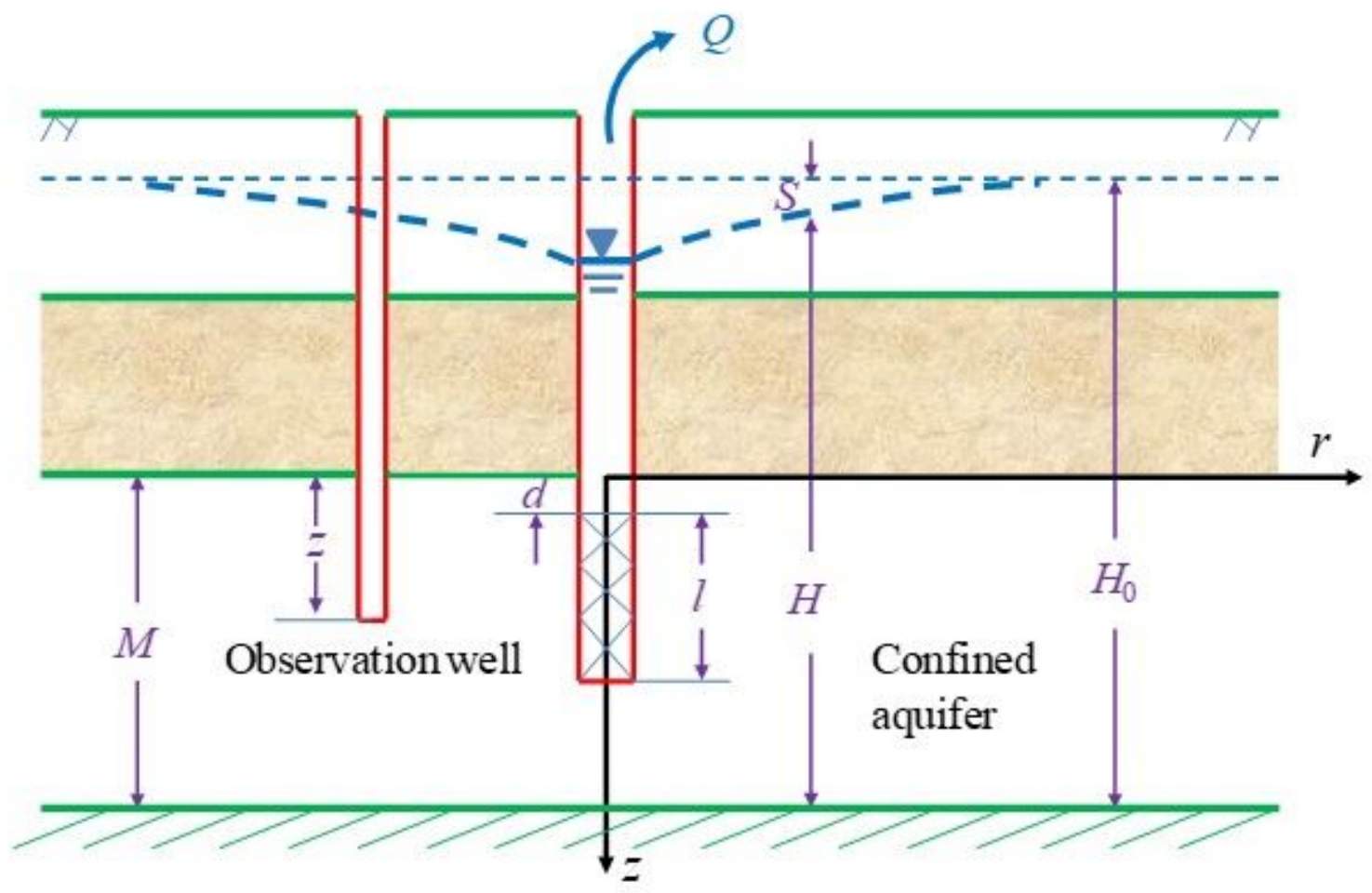

Figure 1

Schematic diagram of partially penetrated well and observation well in confined aquifer

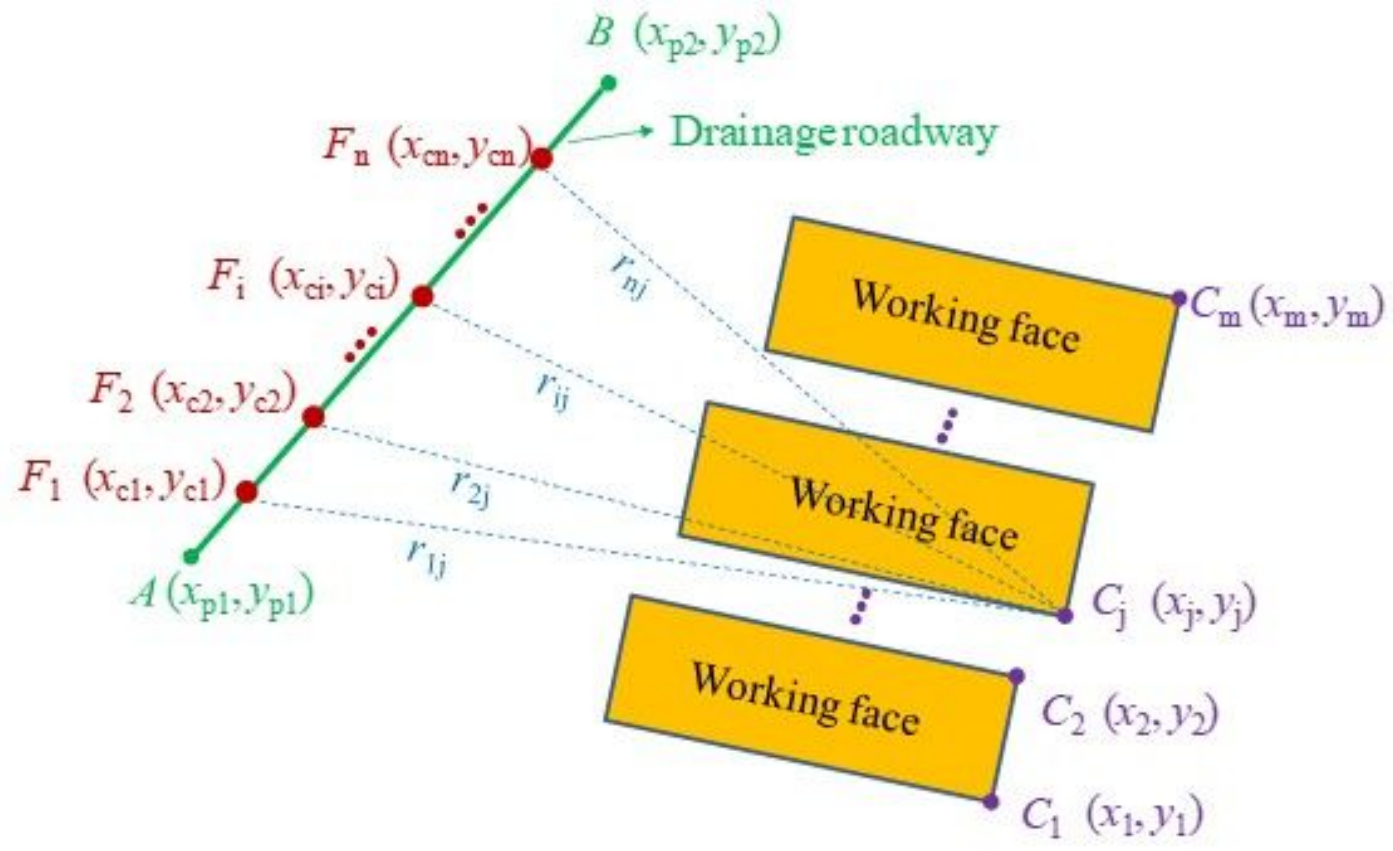


Figure 2

Layout diagram of arrangement of drainage borehole

(a)

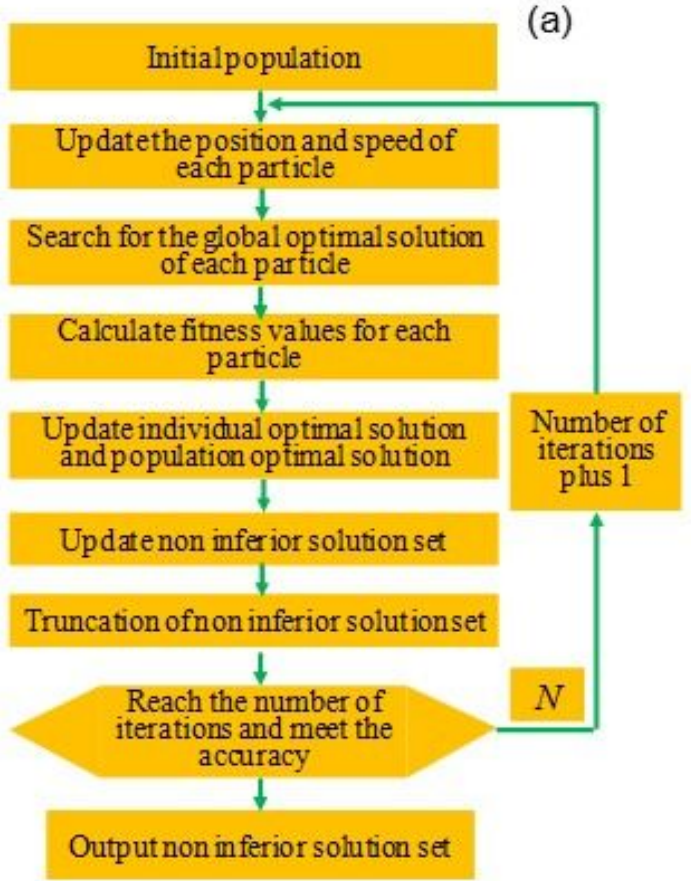

(b)

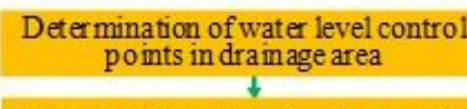

Calculate $H_{\mathrm{s}}$ and $S_{\mathrm{s}}$ of control points

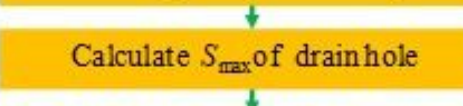

Establish the straight line equation of draina ge roadway $\downarrow$

Constraint condition of $n$

$\downarrow$

Whether the well is incomplete and the spacing is less than $1.5 \mathrm{~m}$

$\downarrow$

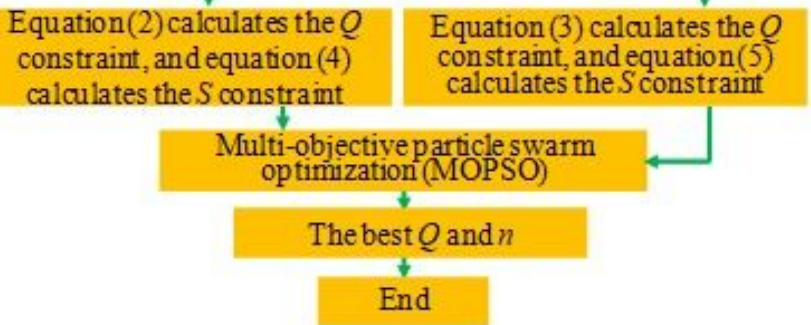

\section{Figure 3}

Calculation flow chart of optimization model. (a) MOPSO algorithm and (b) model establishment and solution 


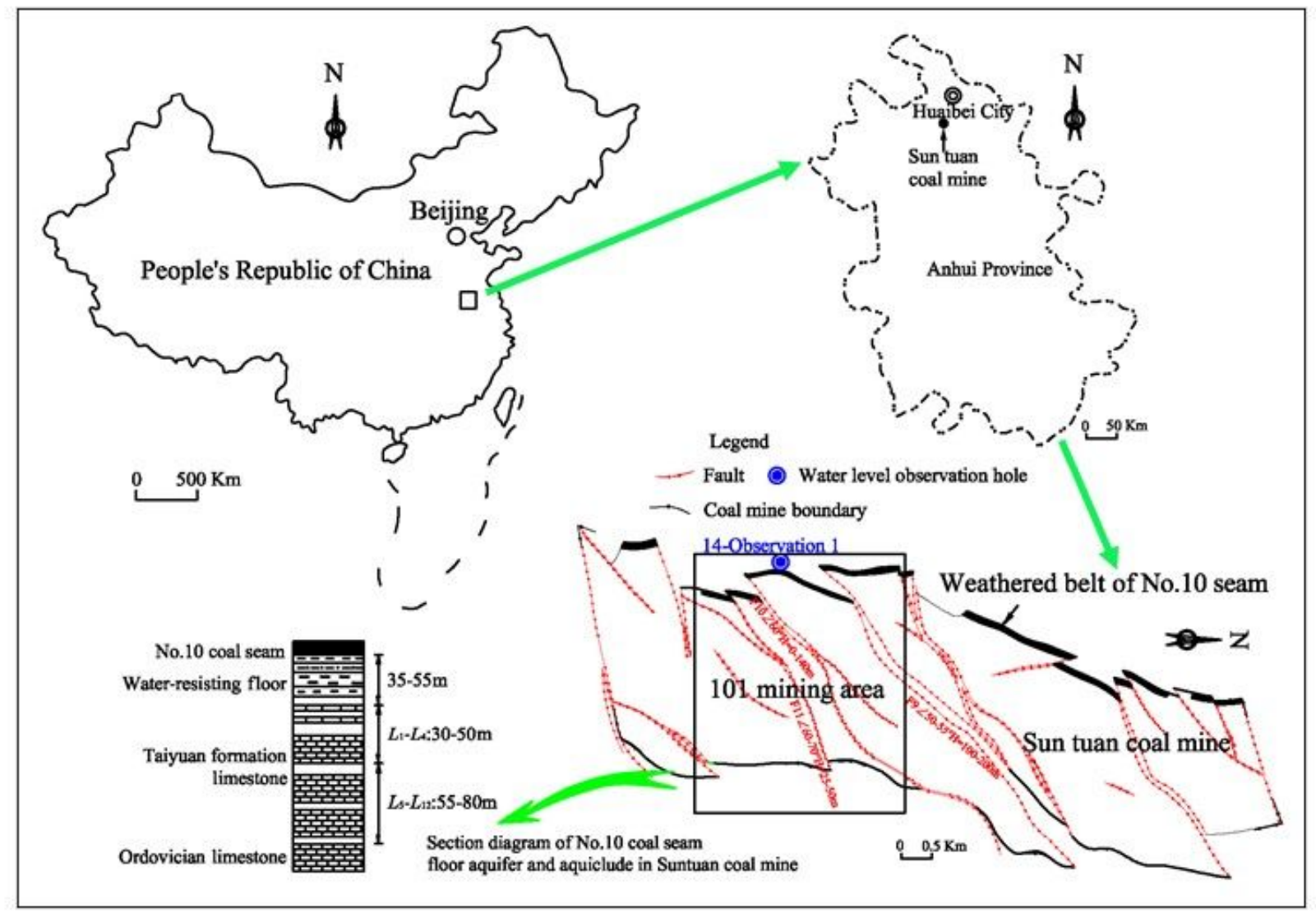

\section{Figure 4}

Location of study area Note: The designations employed and the presentation of the material on this map do not imply the expression of any opinion whatsoever on the part of Research Square concerning the legal status of any country, territory, city or area or of its authorities, or concerning the delimitation of its frontiers or boundaries. This map has been provided by the authors.

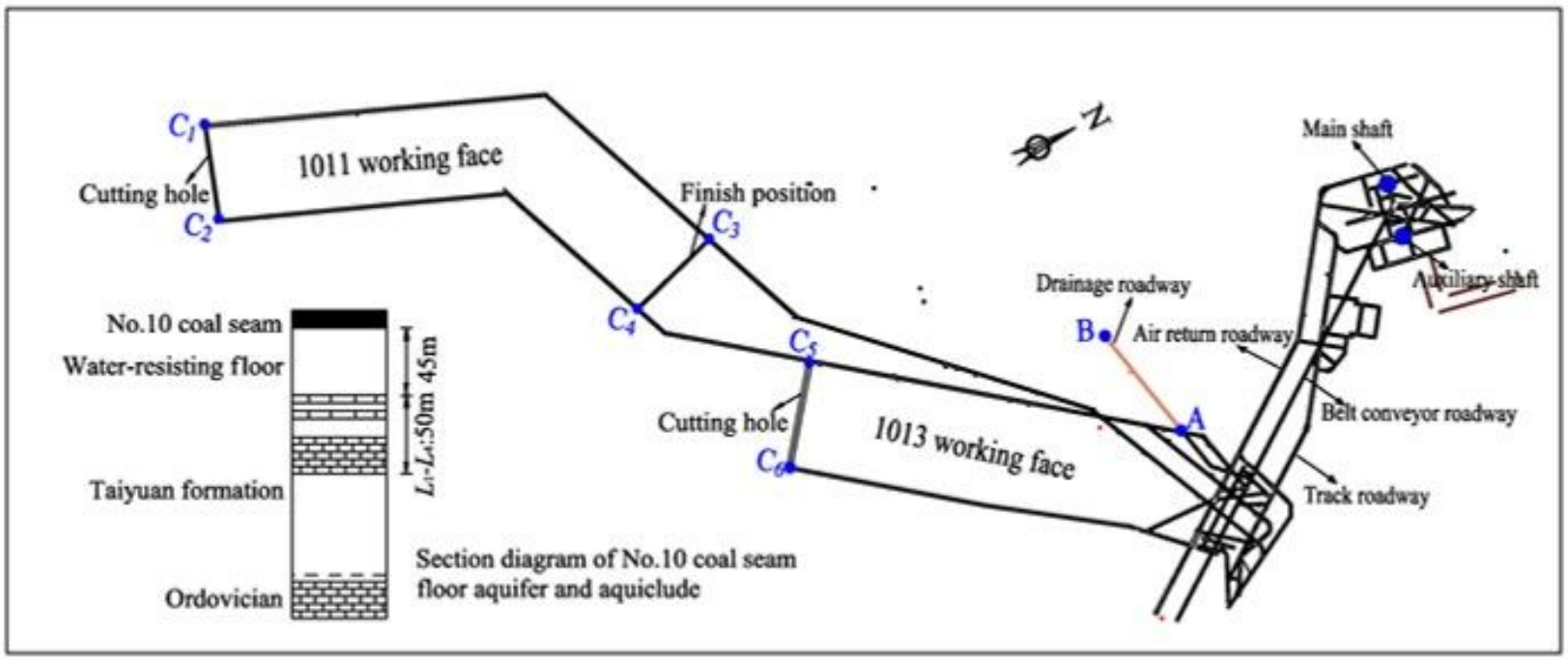

Figure 5 
Location of working face and water level control point in mining area

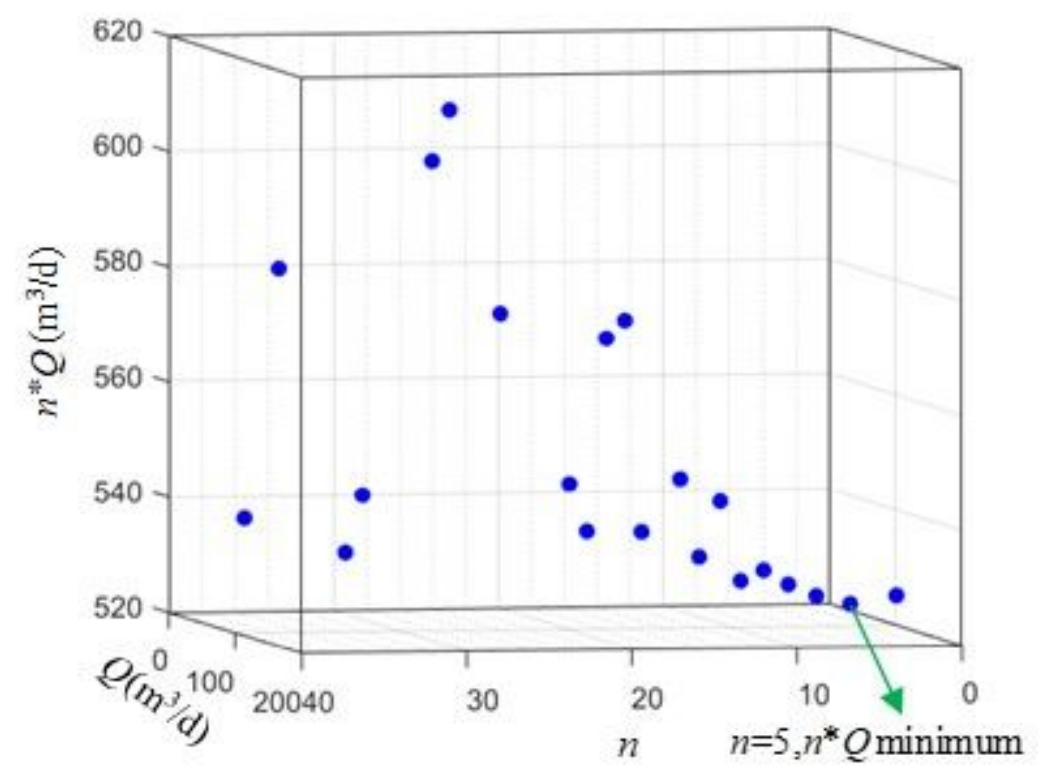

Figure 6

Solutions for all constraints of a fully penetrating well
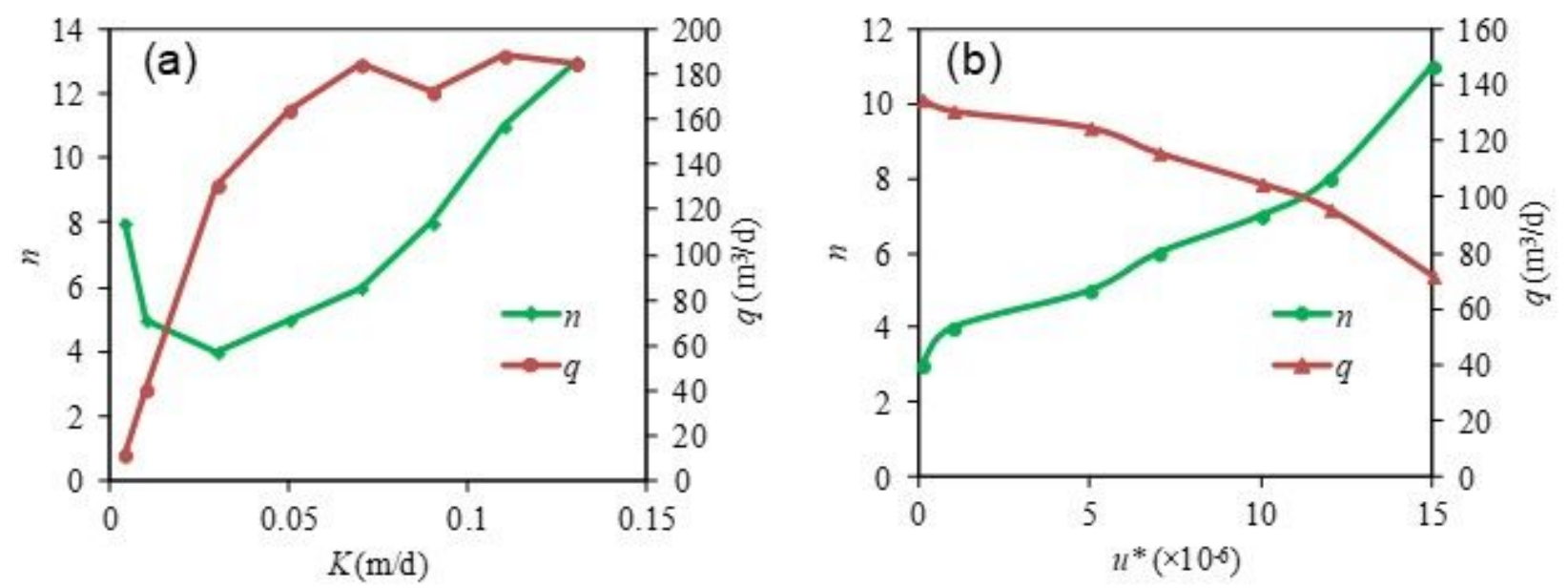

Figure 7

Influence of hydrogeological parameters on optimization model .(a) K (b) $u^{*}(2)$ Water storage coefficient of aquifer 

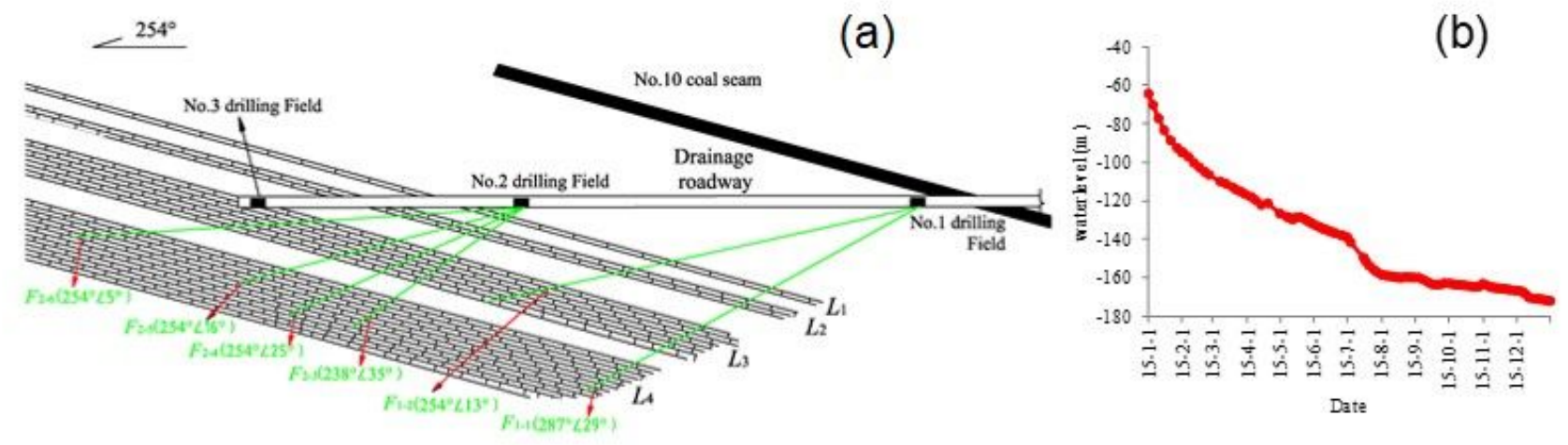

Figure 8

Layout of drainage works and water level change of observation borehole .(a) drainage layout section (b) water level change of 14 observation 1 hole 